\title{
Design and physicochemical characterization of advanced spray-dried tacrolimus multifunctional particles for inhalation
}

This article was published in the following Dove Press journal:

Drug Design, Development and Therapy

31 January 2013

Number of times this article has been viewed

\begin{abstract}
Xiao Wu'
Don Hayes Jr ${ }^{2,3}$

Joseph B Zwischenberger ${ }^{4}$

Robert J Kuhn ${ }^{5}$

Heidi M Mansour ${ }^{1,6}$

'University of Kentucky, College

of Pharmacy, Department of

Pharmaceutical Sciences-Drug

Development Division, Lexington, KY, USA; ${ }^{2}$ The Ohio State University

College of Medicine, Departments of Pediatrics and Internal Medicine, Lung and Heart-Lung Transplant Programs, Nationwide Children's Hospital, Columbus, OH, USA; ${ }^{3}$ The Ohio State University College of Medicine, The Davis Heart and Lung Research Institute, Columbus, OH, USA; ${ }^{4}$ University of Kentucky College of Medicine, Departments of Pediatrics, Biomedical Engineering, Diagnostic Radiology, and Surgery, Lexington, KY, USA; ${ }^{5}$ University of Kentucky, College of Pharmacy, Division of Pharmacy Practice and Science, Lexington, $K Y$, USA; ${ }^{6}$ University of Kentucky, Center of Membrane Sciences, Lexington, KY, USA
\end{abstract}

Correspondence: Heidi M Mansour University of Kentucky, College of Pharmacy, Department of Pharmaceutical Sciences-Drug Development Division, 789 S. Limestone Street, Lexington, KY 40536-0596, USA

Tel + I 859 257|57|

Email heidi.mansour@uky.edu
Abstract: The aim of this study was to design, develop, and optimize respirable tacrolimus microparticles and nanoparticles and multifunctional tacrolimus lung surfactant mimic particles for targeted dry powder inhalation delivery as a pulmonary nanomedicine. Particles were rationally designed and produced at different pump rates by advanced spray-drying particle engineering design from organic solution in closed mode. In addition, multifunctional tacrolimus lung surfactant mimic dry powder particles were prepared by co-dissolving tacrolimus and lung surfactant mimic phospholipids in methanol, followed by advanced co-spray-drying particle engineering design technology in closed mode. The lung surfactant mimic phospholipids were 1,2-dipalmitoyl-sn-glycero-3-phosphocholine and 1,2-dipalmitoyl-sn-glycero-3-[phosphorrac-1-glycerol]. Laser diffraction particle sizing indicated that the particle size distributions were suitable for pulmonary delivery, whereas scanning electron microscopy imaging indicated that these particles had both optimal particle morphology and surface morphology. Increasing the pump rate percent of tacrolimus solution resulted in a larger particle size. X-ray powder diffraction patterns and differential scanning calorimetry thermograms indicated that spray drying produced particles with higher amounts of amorphous phase. X-ray powder diffraction and differential scanning calorimetry also confirmed the preservation of the phospholipid bilayer structure in the solid state for all engineered respirable particles. Furthermore, it was observed in hot-stage micrographs that raw tacrolimus displayed a liquid crystal transition following the main phase transition, which is consistent with its interfacial properties. Water vapor uptake and lyotropic phase transitions in the solid state at varying levels of relative humidity were determined by gravimetric vapor sorption technique. Water content in the various powders was very low and well within the levels necessary for dry powder inhalation, as quantified by Karl Fisher coulometric titration. Conclusively, advanced spray-drying particle engineering design from organic solution in closed mode was successfully used to design and optimize solid-state particles in the respirable size range necessary for targeted pulmonary delivery, particularly for the deep lung. These particles were dry, stable, and had optimal properties for dry powder inhalation as a novel pulmonary nanomedicine.

Keywords: dry powder inhaler (DPI), pulmonary nanomedicine, lung transplant, immunosuppression, lung surfactant, phospholipid colloidal self-assemblies, solid-state particle engineering design, organic solution advanced spray drying

\section{Introduction}

Lung transplantation is a widely accepted strategy to treat end-stage pulmonary disease. However, the long-term survival rate after lung transplantation remains low due to the development of bronchiolitis obliterans, which accounts for approximately $30 \%$ of deaths. ${ }^{1-3}$ Bronchiolitis obliterans syndrome (BOS), the physiological manifestation 
of chronic rejection, is defined as a loss of forced expiratory volume in 1 second of $20 \%$ or greater from the individual patient's maximum post-transplant value. ${ }^{4} \mathrm{BOS}$ and its therapeutic strategies have been recently reviewed by Hayes. ${ }^{5}$ It most likely represents an immune process having multiple risk factors and can be induced following respiratory infection, as recently reported by Hayes et al. ${ }^{6}$ The histopathologic features of bronchiolitis obliterans involve injury and inflammation of epithelial cells and subepithelial structures of small airways, leading to excessive fibroproliferation, seemingly due to ineffective epithelial regeneration. ${ }^{7,8}$

Tacrolimus, a hydrophobic 23-membered macrolide lactone, is one of the most effective immunosuppressive drugs for the prevention of allograft rejection following transplantation of lung. ${ }^{9,10}$ It is a calcineurin inhibitor, which can disrupt the signaling events mediated by calcineurin in $\mathrm{T}$ lymphocytes and consequently inhibit T-cell activation. Tacrolimus (FK506) is a potent immunosuppressive drug marketed as PROGRAF ${ }^{\circledR}$ (Astellas Pharma US, Inc, Northbrook, IL, USA) in a number of countries. It was discovered by Kino and Gotoh of Fujisawa Pharmaceutical Co, in 1984 during a program designed to discover and develop an alternative immunosuppressant to cyclosporine. ${ }^{11}$ It is a macrocyclic lactone derived from the actinomycete Streptomyces tsukubaensis. Although structurally different from cyclosporine, tacrolimus suppresses the immune system by similar mechanisms to cyclosporine. It binds in the cytoplasm with FK binding proteins and interferes with the signal transduction from T-cell surface receptors to the nucleus in lymphocytes, preventing transcription of lymphokine genes involved in T-cell activation. ${ }^{12-15}$

Tacrolimus is $50-100$ times more potent than the immunosuppressant cyclosporine $\mathrm{A}$ in inhibiting T-cell activation. ${ }^{16}$ In addition to its immunosuppressive effect, tacrolimus can act as an anti-inflammatory or antiallergic agent. ${ }^{17-19}$ Clinical trials have shown tacrolimus to be an effective alternative to cyclosporine $\mathrm{A}$ in reducing risk of acute rejection and obliterative bronchiolitis following lung transplantation. In addition to potency differences between tacrolimus and cyclosporine A, there are mechanistic differences, in that tacrolimus inhibits interleukin (IL)-2-induced IL-5 production by human CD4+ T cells and inhibits T-cell proliferation stimulated by IL-2 and IL-7. ${ }^{20}$ In addition, tacrolimus has been demonstrated to be effective in treating BOS and improving lung function in lung transplant recipients who develop BOS while taking cyclosporine A. ${ }^{21}$ However, tacrolimus is a hydrophobic compound and hardly soluble in water $\left(<0.003 \mathrm{mg} / \mathrm{mL}\right.$ at $\left.25^{\circ} \mathrm{C}\right) .{ }^{22}$ Its bioavailability after oral administration is poor and highly variable $(7 \%-32 \%$ in adults and $7 \%-55 \%$ in children). It is almost completely metabolized through the cytochrome P-450 pathway (CYP3A) $)^{12}$ in the liver, with a reported 7.7-15.2 hours in children and $23-46$ hours in adults. ${ }^{23}$

As a result of these pharmacokinetic properties and its extremely narrow therapeutic index, the use of oral tacrolimus is very difficult to manage clinically and requires frequent serum concentration monitoring. The commercially available intravenous dosage form of tacrolimus contains the solubilizing agent polyoxyethylated castor oil, which has been reported to be toxic, so we limit the use of this formulation to a few doses or days of therapy. Systemic side effects such as neurotoxicity and nephrotoxicity complicate the use of tacrolimus in the clinical setting, restricting the permissible dosage. ${ }^{24}$

To overcome these constraints of tacrolimus, involving systemic side effects and an extremely narrow therapeutic index, local immunosuppression by the inhaled route of administration after lung transplantation is a potential approach to directly target the smaller airways where BOS occurs, with improved bioavailability locally to the lung tissue, minimal to no systemic side effects, and improved pulmonary function, as detailed by Hayes et al. ${ }^{25}$ Pulmonary inhalation aerosols have demonstrated success in the targeted delivery of a wide array of pulmonary drugs directly and efficiently to the lungs $\mathrm{s}^{6,25-28}$ and with high patient acceptance. Cyclosporine A has been aerosolized in human lung transplant patients as a nebulized aerosol solution of cyclosporine A dissolved in propylene glycol. ${ }^{29-31}$ We have successfully demonstrated in our recent report the improved response in a lung transplant patient to inhaled nebulized tacrolimus for successful lung immunosuppression while significantly reducing systemic side effects, improving pulmonary functions, improving bioavailability locally in the smaller airways where BOS occurs, and improving patient outcomes. ${ }^{25}$

Pulmonary surfactant is a complex and elegant mixture of specific phospholipids and lung surfactant-specific proteins synthesized and secreted by type II pneumocytes in the lining of the alveoli. The vital role of surfactant in respiration is to decrease the work of breathing by reducing the surface tension to near $0 \mathrm{mN} / \mathrm{m}$ at the air-water interface in the lung. ${ }^{32-35}$ The main constituents of pulmonary surfactant are lipids and lung surfactant-specific proteins, which account for $\sim 90 \%$ and $10 \%$ of the surfactant mass, respectively. ${ }^{36,37}$ Of the lipids, $\sim 85 \%-90 \%$ are specific phospholipids, of which $\sim 80 \%$ are phosphatidylcholine (PC) and $\sim 10 \%$ are phosphatidylglycerol (PG). ${ }^{32,34,35,37,38}$ The fraction of PC accounted for by dipalmitoylphosphatidylcholine (DPPC), a disaturated 16-carbon 
acyl chain PC, is $54 \%$ in humans. ${ }^{38}$ Formation of a DPPC-rich monolayer (a nanoflim) at the interface is thought to reduce surface tension, which reduces the work of breathing and thus facilitates respiration. Surfactant physiological effectiveness also depends on the presence of other components, including anionic lipids such as $\mathrm{PG}$, surfactant proteins, and $\mathrm{Ca}^{2+}$. In addition, these lung surfactant mimic phospholipids, DPPC and 1,2-dipalmitoyl-sn-glycero-3-[phosphor-rac-1-glycerol] sodium salt (DPPG), are used in lung surfactant replacement nanomedicine therapies, controlled release drug delivery, and nanomedicine pulmonary delivery. ${ }^{35,39-43}$

Currently, tacrolimus is delivered to the patient by the oral or intravenous routes. However, these administration routes are associated with severe systemic side effects by lowering the body's ability to mount an immune response. To fulfil the unmet medical need in minimizing the systemic toxicities, pulmonary inhalation using dry powder inhalers (DPIs) is receiving significant attention, as demonstrated by the increasing number of successful DPI products approved for human use..$^{27,44}$

The aim of this novel study is to rationally design, comprehensively characterize, and optimize respirable tacrolimus dry powders for targeted deep lung delivery produced for the first time by the novel engineering process of organic solution advanced spray drying in closed mode. As we reported for pulmonary delivery application, the novel particle design process of organic solution advanced spray drying in closed mode was used. ${ }^{45,46}$ In addition, we report for the first time on the design and optimization of tacrolimus lung surfactant mimic (DPPC/ DPPG) multifunctional microparticles and nanoparticles as inhalable dry powders. They are produced by organic solution advanced co-spray drying in closed mode for targeted deep lung nanomedicine delivery in clinical treatment of acute rejection and obliterative bronchiolitis following lung transplantation. Moreover, the effect of the organic solution closed-mode spraydrying process on the physicochemical properties of these novel microparticulate/nanoparticulate DPI formulations was also systematically and comprehensively characterized.

\section{Experimental Materials}

United States Pharmacopeia-grade tacrolimus powder (99.3\% purity) was purchased from APAC Pharmaceutical LLC (Columbia, MD, USA) with a molecular weight of $804.02 \mathrm{~g} / \mathrm{mol}$ (Figure 1). Synthetic lung surfactant mimic phospholipid powders DPPC and DPPG were purchased

A
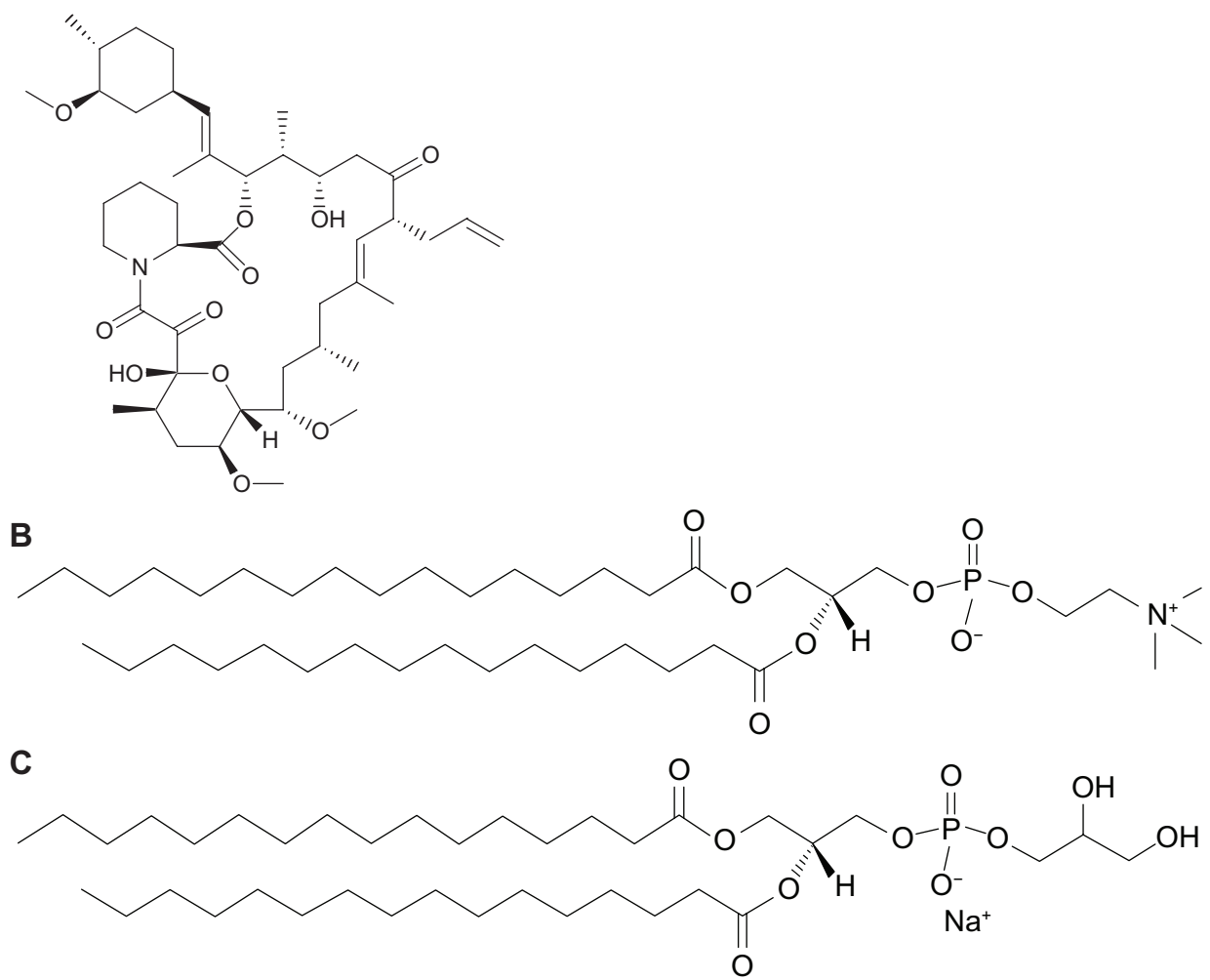

Figure I Chemical structures of (A) lung transplant immunosuppressant drug, tacrolimus, and lung surfactant mimic phospholipids, (B) dipalmitoylphosphatidylcholine, (DPPC), and (C) sodium dipalmitoylphosphatidylglycerol (DPPG). 
from Avanti Polar Lipids, Inc (Alabaster, AL, USA). Their chemical structures are shown in Figure 1. Methanol (highperformance liquid chromatography grade, also meets American Chemical Society specifications, 0.2 micron filtered) was purchased from Fisher Scientific (Pittsburgh, PA, USA). Special anhydrous AQUA STAR methanol for moisture determinations was purchased from EMD Chemicals, Inc (Darmstadt, Germany). Honeywell Riedel-de Haen ${ }^{\circledR}$ Hydranal $^{\circledR}$-Coulomat AD, reagent for Karl Fischer (KF) coulometric titration, was purchased from Sigma-Aldrich (St Louis, MO, USA). All powders were stored in tightly sealed glass desiccators over Drierite ${ }^{\circledR} /$ Indicating Drierite ${ }^{\circledR}$ desiccant (W.A. Hammond Drierite Co. Ltd., Xenia, OH, USA) in the freezer at $-23^{\circ} \mathrm{C}$.

\section{Methods}

Preparation of advanced spray-dried tacrolimus and co-spray-dried tacrolimus lung surfactant mimic particles

Solutions containing tacrolimus were prepared with a total powder mass of $1 \%(\mathrm{w} / \mathrm{v})$ in methanol. The prepared formulations were subsequently spray dried using the Buchi mini spray dryer B-290 with a Buchi high-performance cyclone plus the Buchi inert loop B-295 in closed mode under ultrahigh purity (UHP) nitrogen gas (Scott-Gross Company, Inc, Lexington, KY, USA). As stated in Table 1, and similar to the advanced spray-drying conditions previously reported by these authors, ${ }^{45,46}$ the following spray-drying conditions in closed mode were used: inlet temperature $100^{\circ} \mathrm{C}$, UHP nitrogen atomizing gas flow $601 \mathrm{~L} / \mathrm{h}$, various pump rates rationally selected, and aspirator setting $100 \%$.

Co-spray-dried powders of tacrolimus lung surfactant particles were prepared by dissolving DPPC, DPPG, and tacrolimus simultaneously in methanol with a total powder mass of $1 \%(\mathrm{w} / \mathrm{v})$ followed by co-spray drying. The molar ratio of DPPC:DPPG was $3: 1$, as this is the lung surfactant mimic ratio. The advanced co-spray-drying process was operated under the conditions described previously. All spray-dried and co-spray-dried powders were stored in a desiccator in the freezer until analysis.

\section{Particle sizing and size distribution}

The volume-based particle size and size distribution performed on dry powders were quantified by the Shimadzu SALD-7101 ultraviolet laser diffraction nanoparticle size analyzer (Shimadzu Scientific Instruments, Inc, Columbia, MD, USA). The measured sample containing dry powder suspended in a dispersant was prepared by mixing approximately $40 \mathrm{mg}$ of dry powder in $10 \mathrm{~mL}$ of deionized water in a capped vessel and gently shaking. Tacrolimus is hardly soluble in water $(<0.003 \mathrm{mg} / \mathrm{mL}$ at $\left.25^{\circ} \mathrm{C}\right),{ }^{47}$ as are the synthetic phospholipids. Therefore, water was chosen as a suitable dispersant. Prior to each volume-based particle size and size distribution measurement, a blank cell filled with deionized water was analyzed for background measurement. Subsequently, about $1.5 \mathrm{~mL}$ of the sample containing the dry powder suspended in dispersant was added to the blank, and its volume-based particle size and size distribution were measured. These conditions are similar to those reported previously by these authors..$^{45,48,49}$

\section{Scanning electron microscopy}

Electron microscopy is an important technique in examining dry powder inhalation formulations for respiratory delivery. ${ }^{50,51}$ The shape and surface morphology of raw unprocessed, spray-dried, and co-spray-dried respirable powders were visualized and examined by scanning electron microscopy (SEM) (Hitachi Model S-800, Hitachi Ltd, Tokyo, Japan). Samples were first prepared by placing a very small amount of powder on to an aluminum specimen stub covered with a double-sided adhesive carbon disc, and then sputter coated (Hummer VI Sputtering System by Technics) with gold prior to imaging. Coating was performed at $20 \mathrm{~mA}$ for 3 minutes. These conditions are similar to those reported previously by these authors..$^{45,46,48,49}$

Table I Advanced spray-drying parameters in closed mode of pump rate, inlet temperature, and outlet temperature in the spraydrying process and resultant particle size of dilute organic solution advanced spray-dried tacrolimus dry powder inhalation particles

\begin{tabular}{lllll}
\hline Sample & Pump rate $(\%)$ & Inlet temperature $\left({ }^{\circ} \mathbf{C}\right)$ & Outlet temperature $\left({ }^{\circ} \mathbf{C}\right)$ & Volumetric particle size $(\mu \mathrm{m})$ \\
\hline SDT10 & 10 & 100 & 53 & 1.29 \\
SDT25 & 25 & 100 & 43 & 1.51 \\
SDT50 & 50 & 100 & 30 & 1.54 \\
SDT75 & 75 & 100 & 22 & 1.62 \\
\hline
\end{tabular}

Abbreviations: SDTI0, spray-dried tacrolimus prepared at 10\% pump rate; SDT25, spray-dried tacrolimus prepared at 25\% pump rate; SDT50, spray-dried tacrolimus prepared at 50\% pump rate; SDT75, spray-dried tacrolimus prepared at $75 \%$ pump rate. 


\section{Thermal analysis}

Differential scanning calorimetry (DSC) was performed using the TA DSC Q200 (TA Instruments-Waters LLC, New Castle, DE, USA) equipped with an automated computer-controlled refrigerated cooling system (RSC-90; TA Instruments-Waters LLC), and T-Zero ${ }^{\mathrm{TM}}$ technology. Powder samples (3-5 mg) were carefully weighed and placed in T-Zero ${ }^{\mathrm{TM}}$ alodined aluminum DSC pans (TA instrumentsWaters LLC), which were then hermetically sealed with a T-Zero $^{\text {TM }}$ hermetic sealer (TA instruments-Waters LLC). The phase transition temperature melting point $\left(T_{m}\right)$ of the samples was measured under a $50 \mathrm{~mL} /$ minute dry UHP nitrogen gas (Scott-Gross Company, Inc) purge in DSC. The samples were heated at a rate of $5^{\circ} \mathrm{C} /$ minute from $10^{\circ} \mathrm{C}-300^{\circ} \mathrm{C}$ and also at slower scan rates of $2.5^{\circ} \mathrm{C} /$ minute. At least four melting scans were carried out to ensure $T_{m}$ reproducibility. The measured DSC data were analyzed using a coupled DSC Q200-1740 data station (TA Instruments-Waters LLC). These conditions are similar to those reported previously by these authors. $^{32,34,35,45,46,48,49,52}$

\section{X-ray powder diffraction}

The degree of long-range molecular order (crystallinity) versus disorder (noncrystallinity) for all powders was measured by X-ray powder diffraction (XRPD) using similar conditions reported previously by these authors. ${ }^{45,46,48,49,53}$ Samples of dry powders were gently placed on to a glass slide (Rigaku Corporation, Tokyo, Japan) to form a level surface. Then the glass slide was placed in the $\mathrm{X}$-ray beam path. The $\mathrm{X}$-ray diffraction instrument (slit-detector system) used was Rigaku X-Ray Diffractometer (Rigaku Corporation) with a $\mathrm{Cu}$ source at $44 \mathrm{~mA}$ and $40 \mathrm{kV}$. The scanning range of 5-60 two-theta degrees at room temperature was used at a scanning rate of 2 two-theta degrees per minute at a step rate of 0.04 two-theta degrees.

\section{Cross-polarizing light hot-stage microscopy}

Solid-state phase transitions for the powders were observed under a cross-polarizing light hot-stage microscope (HSM) for the presence and/or absence of birefringency using conditions similar to those reported previously by our group..$^{45,46}$ The digital imaging system consisted of a polarized optical microscope (Olympus BX51; Olympus Corporation, Tokyo, Japan) and a hot stage equipped with a temperature control unit (INSTEC Heater STC200; Instec Inc, Boulder, CO, USA). The microscope was connected to a computer, and SPOT Advanced Software (Diagnostic Instruments, Inc,
Sterling Heights, MI, USA) was used to digitally capture pictures from the microscope. The temperature control unit was also connected to a computer, and Advanced WinTemp v 2.00 software (Instec Inc) was used to set up the heating conditions. Powder samples were mounted on a microscope slide and placed into the sample chamber of the hot stage. The powder samples were then heated from $25^{\circ} \mathrm{C}$ to a final temperature of $300^{\circ} \mathrm{C}$ at a heating scan rate of $5.00^{\circ} \mathrm{C} /$ minute.

\section{Karl Fischer coulometric titration}

Residual water content in the raw, spray-dried, and co-spraydried respirable powders was analytically quantified by $\mathrm{KF}$ coulometric titration method ${ }^{45,46}$ using a KF coulometric titrator (Metrohm 737 KF Coulometer; Metrohm Schweiz AG, Zofingen, Switzerland), equipped with a magnetic stirring device (Metrohm 703Ti Stand; Metrohm Schweiz AG). The KF titrator cell was filled with Honeywell Riedel-de Haen ${ }^{\circledR}$ Hydranal ${ }^{\circledR}$-Coulomat AD reagent, comprising methanol, diethanolamine, imidazole, hydroiodic acid, and sulfur dioxide. The titration sample was prepared by dissolving $50 \mathrm{mg}$ of powders into $100 \mathrm{~mL}$ anhydrous AQUA STAR methanol. Precisely weighed sample solution $(\sim 500 \mathrm{mg})$ was then injected into the KF titrator to react with titration reagent under magnetic stirring. At the end point of titration, the water amount in the analyzed sample was displayed automatically on the titrator. Given that the weight of reacted sample was known, the percentage of water in the sample was calculated.

\section{Gravimetric water vapor sorption}

Gravimetric water vapor isotherms were measured gravimetrically using an automated ultrasensitive microelectronic balance (Cahn) coupled to a computerized VTI SGA-CX Symmetrical Vapor Sorption Analyzer (VTI Corp, Hialeah, FL, USA) under dry UHP nitrogen gas vacuum conditions. Conditions employed were similar to those previously reported by these authors. ${ }^{35,45,52}$ All measurements were made at $25^{\circ} \mathrm{C}$ using a sample size of $1.5-2.5 \mathrm{mg}$. Before the absorption step, samples were dried in situ under dry UHP nitrogen gas vacuum conditions. The criterion used to establish drying equilibrium was a weight change of $0.00 \%$ in a 10-minute interval. At the end of the drying cycle, the sample was exposed to a sequence of increasing relative humidity $(\mathrm{RH})$ levels starting at $0 \% \mathrm{RH}$. Data were logged every 2 minutes or when the weight gain reached $0.01 \%$. Up to a maximum of 3 hours was allowed, which was sufficient to reach absorption equilibrium at each $\mathrm{RH}$ level. The criterion used to establish absorption equilibrium was a weight change of less than or equal to $0.03 \%$ in a 10 -minute interval. 


\section{Results}

\section{Particle size and size distribution}

The particle sizes of spray-dried tacrolimus particles are shown in Table 1. The mean diameter of organic solution advanced spray-dried tacrolimus particles ranged from $1.29 \mu \mathrm{m}$ to $1.62 \mu \mathrm{m}$, which is suitable for targeted inhalation delivery as dry powders. In particular, particles in this size range can effectively target and reach the deep bronchiolar and alveolar regions. ${ }^{27,39,40,44,45,54,55}$ The size distributions for the various batches were narrow and unimodal. These results indicate that the spray-drying pump rate influences the size of spray-dried particles. Increasing the pump rate of drug solution resulted in a larger particle size. The results also indicate that when the inlet temperature, spray gas flow rate, and aspirator percentage of the spray-drying process remained constant, different pump rates resulted in different outlet temperatures, as shown in Table 1.

Table 2 lists the compositions and particle size of co-spray-dried tacrolimus lung surfactant mimic powder formulations. In laser diffraction particle size analysis, the average size of co-spray-dried tacrolimus lung surfactant mimic particles was found to be $2.46 \mu \mathrm{m}$ and $2.55 \mu \mathrm{m}$, as tabulated in Table 2. In particular, particles in this size range can effectively target and reach the deep bronchiolar and alveolar regions. . $7,39,40,44,45,54,55$ The size distributions for the various batches were narrow and unimodal. The average particle size for the various batches did not show a significant difference.

\section{SEM}

The SEM micrographs of tacrolimus before and after spray drying are shown in Figure 2. The raw unprocessed tacrolimus particles have very large dimensions and a broad size distribution. The organic solution advanced spray-dried tacrolimus contains spherical particles with a relatively smooth surface, which are two essential particle properties for inhalation delivery of dry powders. ${ }^{45,55,56}$ The particle size observed in their SEM images is in agreement with that measured by laser diffraction.
The SEM micrographs of raw tacrolimus and tacrolimus particles are shown in Figure 3. The organic solution advanced co-spray-dried tacrolimus lung surfactant mimic particles (Figure 3B and C) successfully formed with equivalent sphere particle morphology with a corrugated surface morphology, which are two essential particle properties for inhalation delivery of dry powders. The particle size observed by SEM is in excellent agreement with that measured by laser diffraction.

\section{Thermal analysis by DSC}

The thermograms of raw tacrolimus and organic solution advanced spray-dried tacrolimus are shown in Figure 4. Analysis of the thermogram for raw tacrolimus showed one sharp endothermic peak with an onset temperature at $134^{\circ} \mathrm{C}$, indicative of melting and the crystalline nature of the raw unprocessed drug, which was confirmed by XRPD. DSC thermal analysis of the spray-dried powders did not exhibit the characteristic endothermic melting peak, suggesting a loss of crystallinity into a noncrystalline form (likely amorphous) following the organic solution advanced spray-drying process.

The thermograms of raw tacrolimus and organic solution advance co-spray-dried lung surfactant mimic powders are shown in Figure 5. DPPC powders exhibit two endothermic phase transitions at $66.9^{\circ} \mathrm{C}$ and $73^{\circ} \mathrm{C}$, corresponding to the gel-to-ripple bilayer pretransition and to the bilayer main transition $T_{m}$ (ie, due to the hydrophobic acyl chain melting event) between the rippled-gel and liquid crystalline phases, respectively. ${ }^{52}$ DPPG powders showed three endothermic phase transitions consisting of two low-enthalpy pretransitions at $\sim 55.3^{\circ} \mathrm{C}$ and $\sim 79.5^{\circ} \mathrm{C}$ and a high-enthalpy main phase transition at $125^{\circ} \mathrm{C}$, which correspond to the crystalto-gel bilayer phase transition, gel-to-ripple bilayer phase transition, and rippled-to-liquid crystalline bilayer main phase transition $\left(T_{m}\right)$, respectively. ${ }^{52} \mathrm{Co}$-spray-dried samples of tacrolipo25 and tacrolipo75 containing lung surfactant mimic DPPC/DPPG (3:1) exhibit the main bilayer phase transition temperature at $66.2^{\circ} \mathrm{C}$ and $67.4^{\circ} \mathrm{C}$, respectively,

Table 2 Compositions and average particle size of tacrolimus lung surfactant mimic dry powder inhalation formulations by advanced co-spray drying from organic solution in closed mode

\begin{tabular}{llllll}
\hline Sample & Abbreviation & $\begin{array}{l}\text { Drug content } \\
(\text { mole \%) }\end{array}$ & $\begin{array}{l}\text { DPPC } \\
\text { content (\%) }\end{array}$ & $\begin{array}{l}\text { DPPG } \\
\text { content (\%) }\end{array}$ & $\begin{array}{l}\text { Volumetric particle } \\
\text { size }(\mu \mathbf{m})^{\mathbf{a}}\end{array}$ \\
\hline Tacrolimus: DPPC/DPPG & Tacrolipo25 & 25 & 56.25 & 18.75 & $2.46 \pm 0.07$ \\
Tacrolimus: DPPC/DPPG & Tacrolipo75 & 75 & 18.75 & 6.25 & $2.55 \pm 0.11$ \\
\hline
\end{tabular}

Note: a Mean \pm standard deviation $(n=5)$.

Abbreviations: DPPC, dipalmitoylphosphatidylcholine; DPPG, sodium dipalmitoylphosphatidylglycerol. 

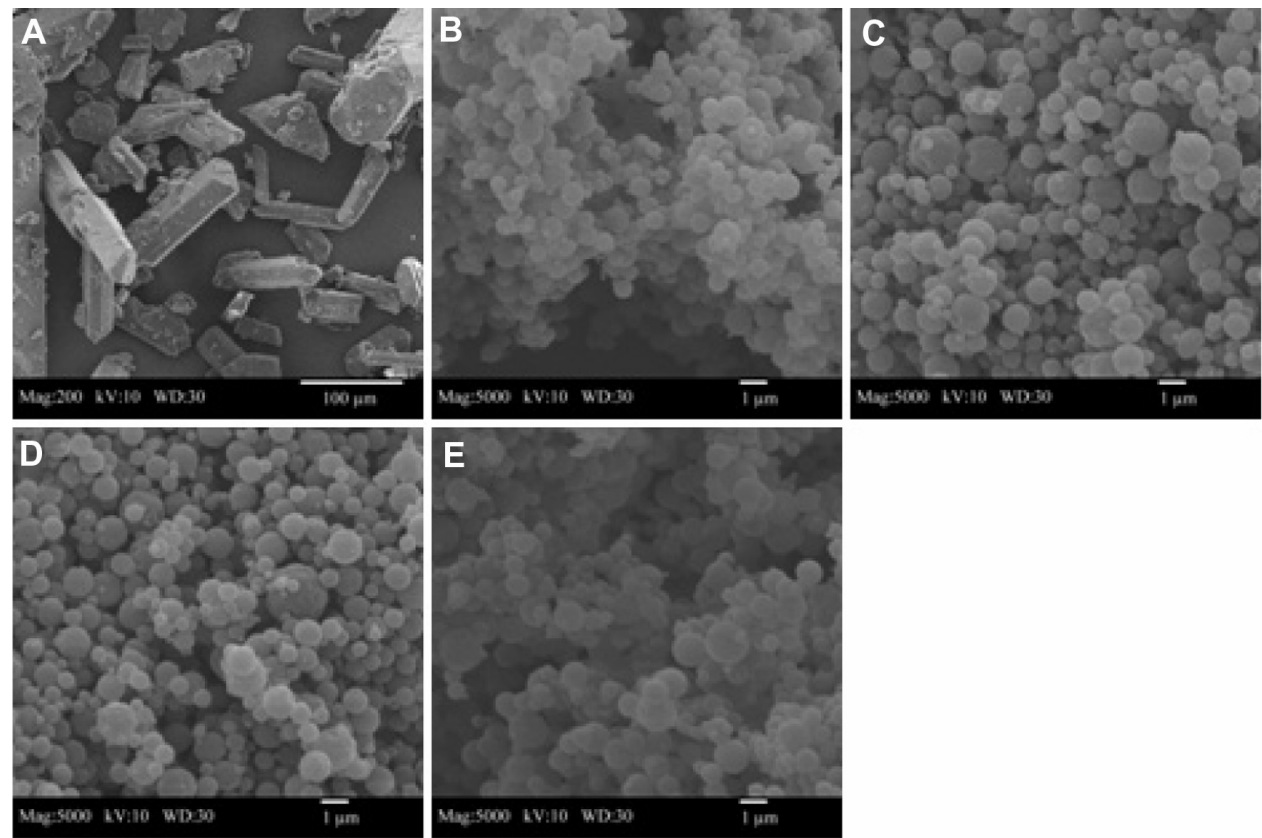

Figure 2 Scanning electron micrographs of $(\mathbf{A})$ raw unprocessed tacrolimus, (B) spray-dried tacrolimus prepared at $10 \%$ pump rate, (C) spray-dried tacrolimus prepared at $25 \%$ pump rate, (D) spray-dried tacrolimus prepared at $50 \%$ pump rate, and (E) spray-dried tacrolimus prepared at $75 \%$ pump rate.

which are slightly below the $T_{m}$ values of pure DPPC and DPPG powders. All co-spray-dried lung surfactant mimic particles did not exhibit the characteristic tacrolimus endothermic melting peak, suggesting a loss of crystallinity in tacrolimus following organic solution advanced spray drying.

\section{XRPD}

Diffractograms for raw and spray-dried tacrolimus at different pump rates are shown in Figure 6. Raw tacrolimus reveals sharp and narrow diffraction peaks at 5-30 twotheta degrees, which are characteristic of a high degree of long-range molecular order (ie, crystallinity). In contrast, the diffractograms of spray-dried tacrolimus powders lack any significant sharp peaks, which are indicative of the loss in long-range molecular order, which along with thermal analysis suggests formation of the amorphous state. Such observations further confirm the crystallinity in commercial raw tacrolimus and the amorphous state in the organic solution advanced spray-dried tacrolimus powders.

Diffractograms for the co-spray-dried respirable powders are shown in Figure 7. Raw tacrolimus (highest curve) reveals apparent diffraction peaks at 5-30 two-theta degrees. DPPC and DPPG show a distinct peak in the range of 20-25 two-theta degrees, which is a characteristic range indicative of the phospholipid bilayer structure. ${ }^{57}$ This characteristic peak is also clearly evident in the co-spray-dried respirable powders, which indicate preservation of the phospholipid bilayer structure in these co-spray-dried powders.
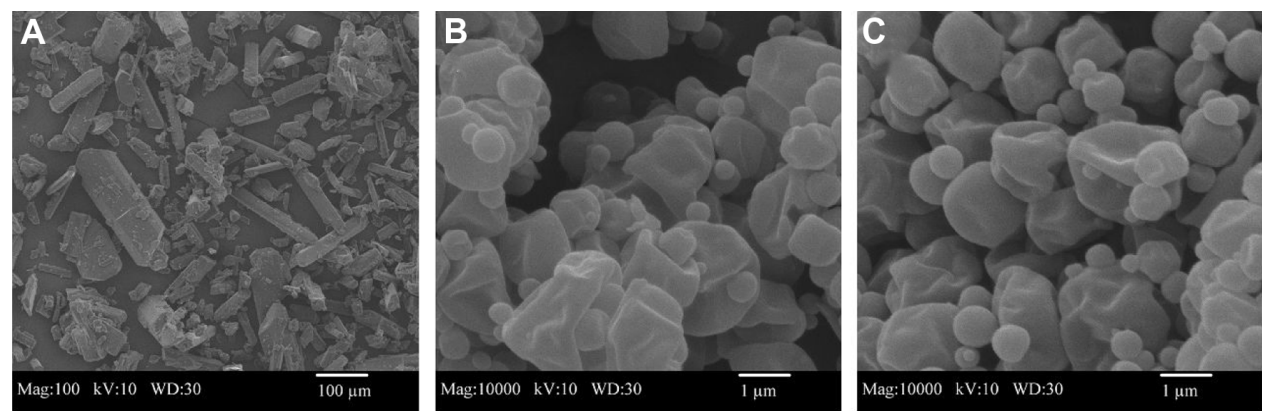

Figure 3 Scanning electron micrographs of (A) raw unprocessed tacrolimus, (B) tacrolipo25, and (C) tacrolipo75. 


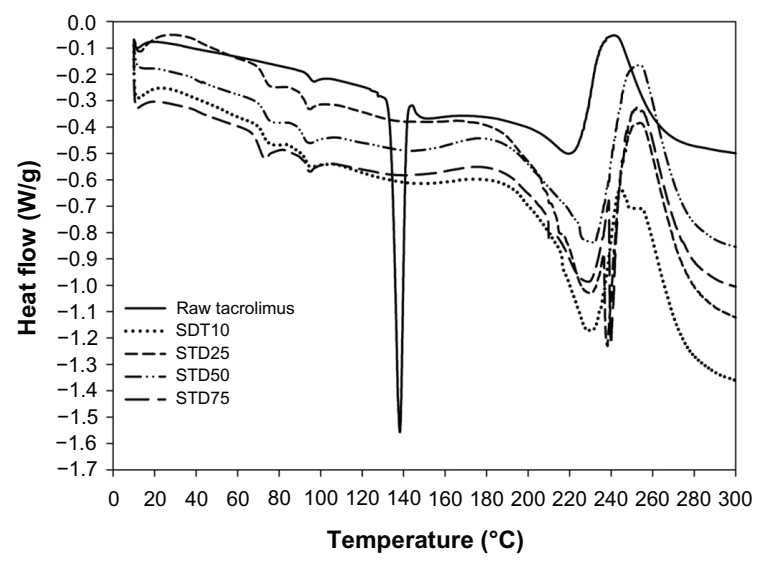

Figure 4 Differential scanning calorimetry thermograms at $5.00^{\circ} \mathrm{C} /$ minute heating scan rate of raw tacrolimus and organic solution advanced spray-dried tacrolimus for dry powder inhalation.

Abbreviations: SDTI0, spray-dried tacrolimus prepared at $10 \%$ pump rate; SDT25, spray-dried tacrolimus prepared at $25 \%$ pump rate; SDT50, spray-dried tacrolimus prepared at 50\% pump rate; SDT75, spray-dried tacrolimus prepared at $75 \%$ pump rate.

\section{Cross-polarizing light HSM}

Figure 8 shows the polarized optical microscope images for the phase transitions of raw tacrolimus. At room temperature, raw tacrolimus exhibited crystal forms, as shown in Figure 8A. When temperature increased to $133.8^{\circ} \mathrm{C}$, tacrolimus started to melt (Figure $8 \mathrm{~B}$ ). The onset temperature coincided with its melting recorded by DSC. Figure $8 \mathrm{C}-\mathrm{F}$ shows the melting process. Before tacrolimus transformed into a liquid state, it also displayed a liquid crystal state, as shown in Figure 8D-F. The endothermic peak of crystalline transformation into liquid crystal was also present in the DSC thermograph of tacrolimus at slow heating scan rates of $2.50^{\circ} \mathrm{C} /$ minute versus $5.00^{\circ} \mathrm{C} /$ minute, as shown

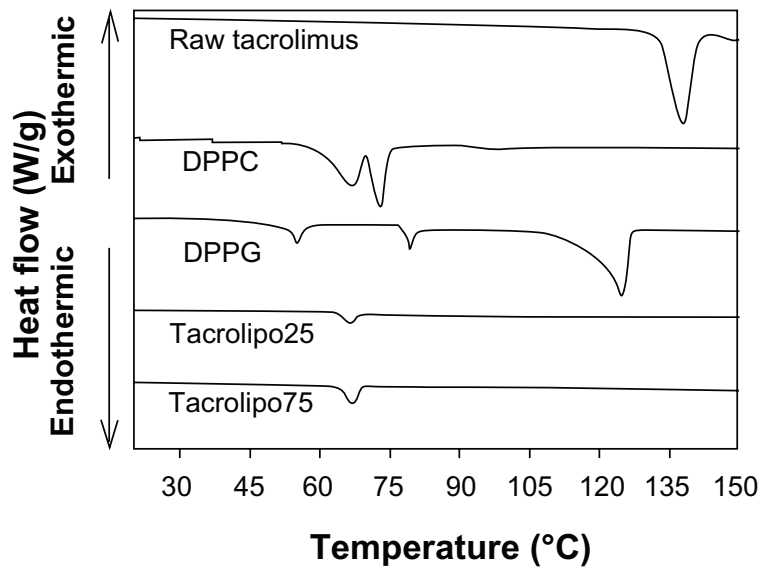

Figure 5 Differential scanning calorimetry thermograms at $5.00^{\circ} \mathrm{C} /$ minute heating scan rate of raw tacrolimus, pure dipalmitoylphosphatidylcholine (DPPC), pure sodium dipalmitoylphosphatidylglycerol (DPPG), and organic solution advanced cospray-dried lung surfactant mimic inhalable particles (tacrolipo25 and tacrolipo75) for dry powder inhalation.

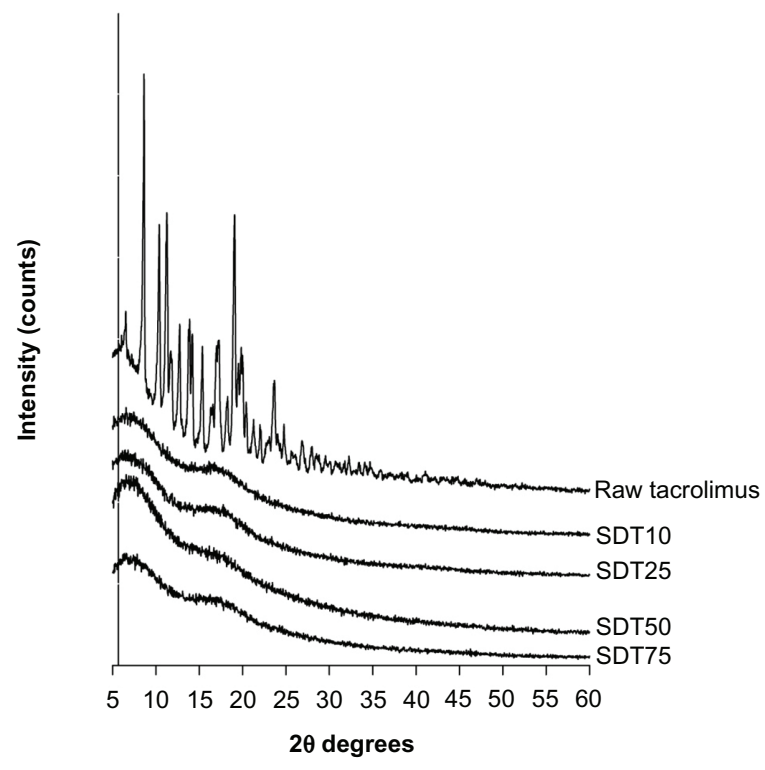

Figure 6 X-ray powder diffractograms of raw tacrolimus and organic solution advanced spray-dried tacrolimus for dry powder inhalation.

Abbreviations: SDT10, spray-dried tacrolimus prepared at 10\% pump rate; SDT25, spray-dried tacrolimus prepared at $25 \%$ pump rate; SDT50, spray-dried tacrolimus prepared at 50\% pump rate; SDT75, spray-dried tacrolimus prepared at $75 \%$ pump rate.

in Figure 9. At $2.50^{\circ} \mathrm{C} /$ minute and $5.00^{\circ} \mathrm{C} /$ minute, DSC thermograms show a small endothermic peak at $\sim 147^{\circ} \mathrm{C}$ following the main phase transition, indicative of the liquid crystal state. This is the first time that such a thermal event in tacrolimus has been reported. However, interestingly, the small peak was not readily observed at a heating scan rate of $10.00^{\circ} \mathrm{C} /$ minute. This indicates that only a slow scan rate of $2.50^{\circ} \mathrm{C}$ /minute can reveal this important liquid crystalline material property involved in the phase transition of crystalline tacrolimus. Figure $8 \mathrm{G}$ shows the liquid state of

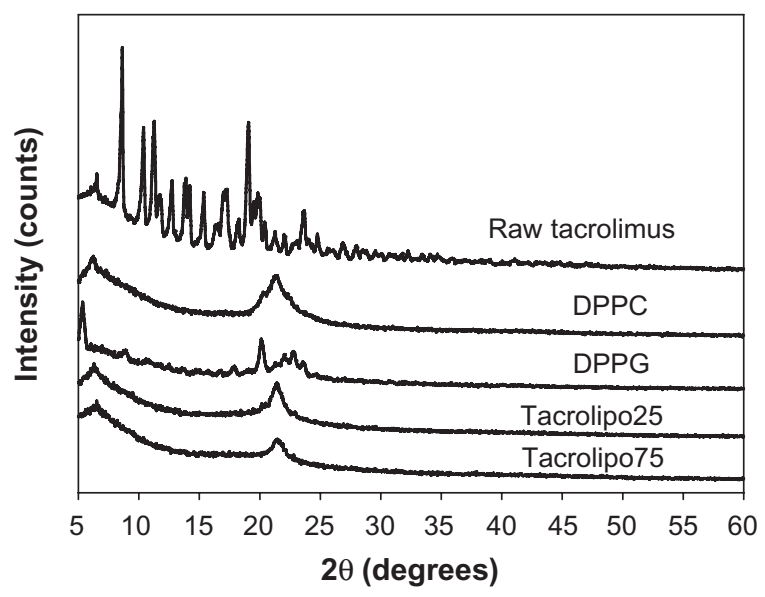

Figure 7 X-ray powder diffraction patterns of raw tacrolimus, pure dipalmitoylphosphatidylcholine (DPPC), pure sodium dipalmitoylphosphatidylglycerol (DPPG), and organic solution advanced co-spray-dried lung surfactant mimic particles (tacrolipo25 and tacrolipo75) for dry powder inhalation. 

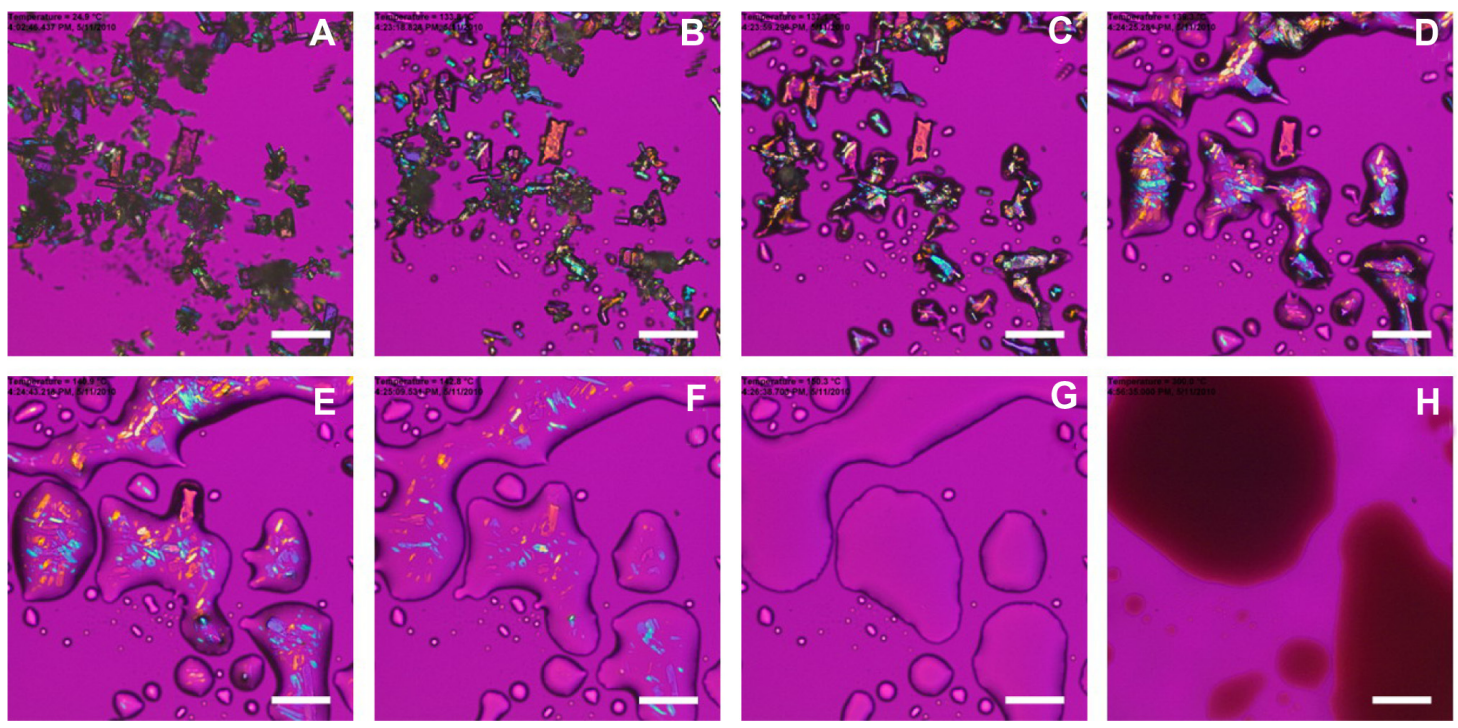

Figure 8 Cross-polarized light optical microscope images of the phase transitions for raw tacrolimus. The samples were heated from $25^{\circ} \mathrm{C}$ to $300^{\circ} \mathrm{C}$ at $5.00^{\circ} \mathrm{C} / m i n u t e$. The temperature for each graph is $(\mathbf{A}) 24.9^{\circ} \mathrm{C}$, (B) $133.8^{\circ} \mathrm{C}$, (C) $137.1^{\circ} \mathrm{C},(\mathbf{D}) 139.3^{\circ} \mathrm{C},(\mathbf{E}) 140.9^{\circ} \mathrm{C},(\mathbf{F}) 142.8^{\circ} \mathrm{C},(\mathbf{G}) 150.3^{\circ} \mathrm{C}$, and (H) $300.0^{\circ} \mathrm{C}$.

Note: Scale bar represents $0.2 \mathrm{~mm}$.

tacrolimus after melting. At $225^{\circ} \mathrm{C}$, tacrolimus started to degrade (Figure $8 \mathrm{H}$ ), which was consistent with the DSC thermal analysis (Figures 4 and 9).

Figure 10 shows the cross-polarized optical microscope images for the phase transitions of organic solution advanced spray-dried tacrolimus. Various spray-dried batches generated similar images. Hence, representative images from the spray-dried tacrolimus prepared at $50 \%$ pump rate powders are shown here. As expected, no melting point was observed, which was consistent with the amorphous nature of these respirable tacrolimus spraydried particles. At $\sim 120^{\circ} \mathrm{C}$, tacrolimus existed as a liquid (Figure $10 \mathrm{G}$ ), and at $\sim 300^{\circ} \mathrm{C}$ it degraded (Figure $10 \mathrm{H}$ ), which is consistent with the DSC thermal analysis (Figure 4).

\section{KF coulometric titration}

The residual water content in raw unprocessed tacrolimus versus organic solution advanced spray-dried tacrolimus powder at different pump rates were quantified analytically by KF and are shown in Table 3 . The water content before spray drying was very low at $\sim 1.84 \%$ for the raw unprocessed tacrolimus, which is consistent for a hydrophobic drug. Following advanced spray drying from organic solution, the residual water content remaining was successfully reduced remarkably even further to $<0.7 \%$. This is well within recommended levels for respirable dry powders for superior aerosolization and enhanced stability.
As shown in Table 4, before spray drying, the water content of raw DPPC and DPPG powders was $\sim 1.95 \%$ and $0.51 \%$, respectively. After organic solution advanced co-spray drying, the residual water content was successfully reduced even further to $\sim 1 \%$. Again, this is well within recommended levels for respirable dry powders for superior aerosolization and enhanced stability.

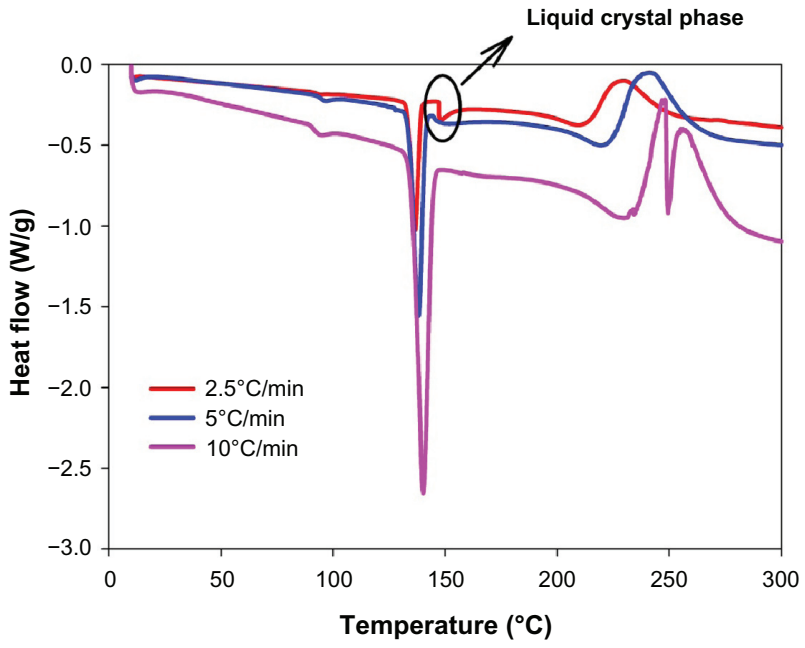

Figure 9 The effect of scanning rate on differential scanning calorimetry (DSC) thermograph of raw tacrolimus.

Notes: The liquid crystal phase transition is highlighted in the black circle. It is shown that when a low scanning rate $\left(2.50^{\circ} \mathrm{C} / \mathrm{min}\right.$ and $\left.5.00^{\circ} \mathrm{C} / \mathrm{min}\right)$ is used, the endothermic peak indicating the liquid crystal phase can be observed in the DSC thermograph. However, with a scanning rate of $10.00^{\circ} \mathrm{C} /$ minute, liquid crystal phase transition is not present in the DSC thermograph. 

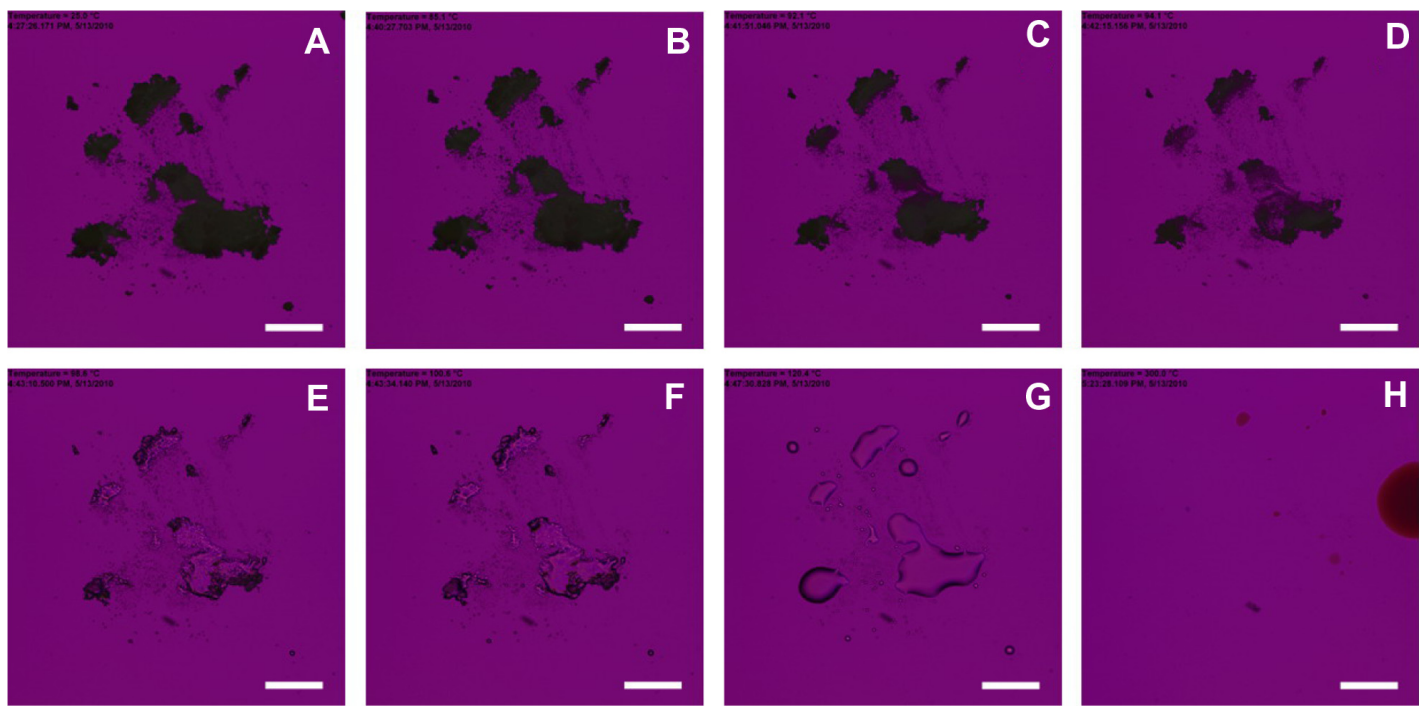

Figure 10 Cross-polarized light optical microscope images for the phase transitions of spray-dried tacrolimus prepared at $50 \%$ pump rate. The samples were heated from $25^{\circ} \mathrm{C}$ to $300^{\circ} \mathrm{C}$ at $5^{\circ} \mathrm{C} /$ minute. The temperature for each graph is $(\mathbf{A}) 25^{\circ} \mathrm{C},(\mathbf{B}) 85.1^{\circ} \mathrm{C}$, (C) $92.1^{\circ} \mathrm{C},(\mathbf{D}) 94.1^{\circ} \mathrm{C},(\mathbf{E}) 98.6^{\circ} \mathrm{C},(\mathbf{F}) 100.6^{\circ} \mathrm{C},(\mathbf{G}) 120.4^{\circ} \mathrm{C}$, and $(\mathbf{H}) 300.0^{\circ} \mathrm{C}$. Note: Scale bar represents $0.2 \mathrm{~mm}$.

\section{Gravimetric water vapor sorption}

As shown in Figure 11, when the RH level exceeded just 20\%, which is a low RH level, raw tacrolimus did not absorb any additional water vapor (ie, a plateau is reached at $\sim 20 \% \mathrm{RH}$ and remains relatively constant thereafter), due to its crystalline nature. This is a characteristic property of crystalline powders. This plateau value is also in excellent agreement with the KF value for raw tacrolimus powder. Contrastingly, the spray-dried powders do not exhibit a significant plateau region over any $\mathrm{RH}$ range, and continue to take up more water vapor at RH levels of $90 \%$ and higher under equilibrium conditions, which is characteristic of amorphous powders.

As shown in Figure 12, at low RH levels of 0\%-20\% RH, the absorption profiles were similar for DPPC, raw tacrolimus, tacrolipo25, and tacrolipo75. Sodium DPPG absorbed much less water, due to its tightly packed bilayer as a result

Table 3 Water content (w/w\%) of tacrolimus before and after organic solution advanced spray drying

\begin{tabular}{ll}
\hline Sample & $\begin{array}{l}\text { Sample water } \\
\text { content }(\mathbf{w} / \mathbf{w} \%)^{\mathbf{a}}\end{array}$ \\
\hline Raw tacrolimus & $1.83 \pm 0.21$ \\
SDT10 & $0.40 \pm 0.18$ \\
SDT25 & $0.40 \pm 0.08$ \\
SDT50 & $0.44 \pm 0.20$ \\
SDT75 & $0.65 \pm 0.12$ \\
\hline
\end{tabular}

Note: a Mean \pm standard deviation $(n=3)$.

Abbreviations: SDTI0, spray-dried tacrolimus prepared at 10\% pump rate; SDT25, spray-dried tacrolimus prepared at $25 \%$ pump rate; SDT50, spray-dried tacrolimus prepared at $50 \%$ pump rate; SDT75, spray-dried tacrolimus prepared at $75 \%$ pump rate. of favorable electrostatic interactions between the cationic sodium ion and anionic polar headgroup, and is in good agreement with our earlier report..$^{52} \mathrm{At}$ intermediate $\mathrm{RH}$ regions, the weight change percentage of DPPG showed a plateau, with an increasing RH between $20 \%-70 \%$, but increased significantly when the $\mathrm{RH}$ exceeded $\sim 70 \%$. The plateau region is indicative of a phase transition, as has been described earlier by these authors. ${ }^{52} \mathrm{~A}$ similar profile was observed for DPPC. When RH was between $20 \%$ and $65 \%$, the percentage weight change of DPPC was higher than DPPG and is in good agreement with our earlier report. ${ }^{52}$ When RH level exceeded $\sim 65 \%$, the percentage weight change of DPPC increased significantly with an increasing $\mathrm{RH}$ and is in good agreement with our earlier report. ${ }^{52}$ For the organic solution advanced co-spraydried tacrolipo25 and tacrolipo 75 respirable lung surfactant mimic powders, the profiles were similar to each another and

Table 4 Water content (w/w\%) of tacrolimus, lung surfactant mimic phospholipids, and spray-dried powder inhalation formulations before and after organic solution advanced co-spray drying

\begin{tabular}{ll}
\hline Sample & $\begin{array}{l}\text { Sample water } \\
\text { content }(\mathbf{w} / \mathbf{w} \%)^{\mathbf{a}}\end{array}$ \\
\hline Raw tacrolimus & $1.83 \pm 0.17$ \\
DPPC & $1.95 \pm 0.48$ \\
DPPG & $0.51 \pm 0.16$ \\
Tacrolipo25 & $1.07 \pm 0.82$ \\
Tacrolipo75 & $1.13 \pm 0.39$ \\
\hline
\end{tabular}

Note: aean \pm standard deviation $(n=5)$.

Abbreviations: DPPC, dipalmitoylphosphatidylcholine; DPPG, sodium dipalmitoylphosphatidylglycerol. 


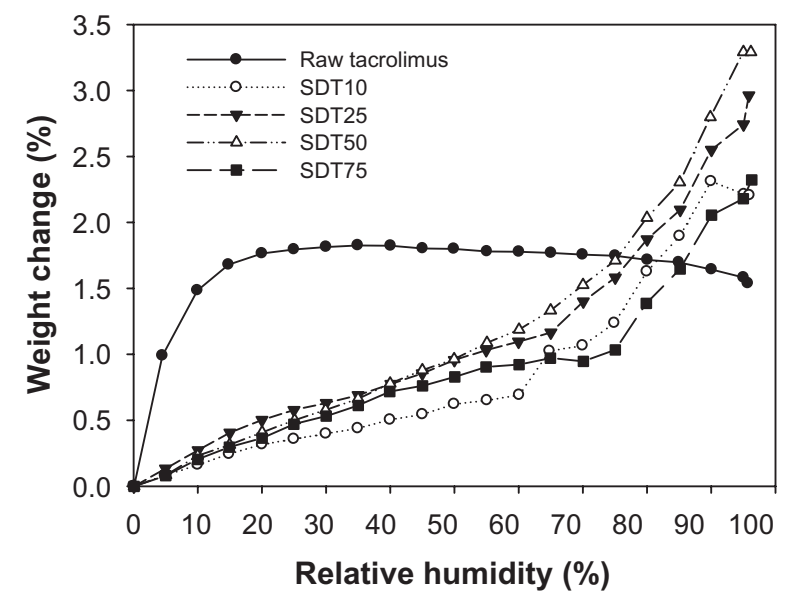

Figure I I Gravimetric water vapor absorption isotherms for raw tacrolimus versus organic solution advanced spray-dried dry powder inhalation tacrolimus at various spray-drying pump rates.

Abbreviations: SDTI0, spray-dried tacrolimus prepared at 10\% pump rate; SDT25, spray-dried tacrolimus prepared at $25 \%$ pump rate; SDT50, spray-dried tacrolimus prepared at 50\% pump rate; SDT75, spray-dried tacrolimus prepared at $75 \%$ pump rate.

approached the raw DPPC absorption curve when the RH level exceeded $\sim 70 \% \mathrm{RH}$.

The maximal absorption percentage weight change values at the $\mathrm{RH}$ levels found in the lung of $90 \%$ and $93 \%$ are shown in Table 5. This is the maximal water percentage absorbed by the respirable powders and is relatively low, as would be expected for hydrophobic powders.

\section{Discussion}

Clinical treatment of acute rejection and obliterative bronchiolitis in lung transplant recipients by systemically administrated tacrolimus has proven to be ineffective, per-

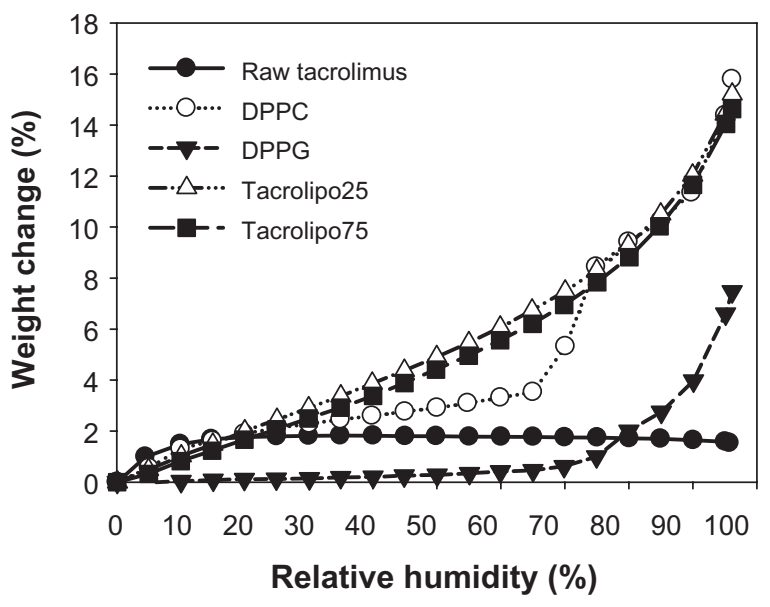

Figure 12 Gravimetric water vapor absorption isotherms for raw tacrolimus, pure dipalmitoylphosphatidylcholine (DPPC), pure sodium dipalmitoylphosphatidylglycerol (DPPG) and organic solution advanced co-spray-dried lung surfactant mimic particles of tacrolimus for dry powder inhalation (tacrolipo25 and tacrolipo75).
Table 5 The maximal weight change percentages by water absorption at $90 \%$ and $93 \% \mathrm{RH}$ for raw materials and organic solution advanced spray-dried tacrolimus lung surfactant mimic particles for dry powder inhalation

\begin{tabular}{lll}
\hline Sample & $\begin{array}{l}\text { Maximum wt\% } \\
\text { change at } \mathbf{9 0 \%} \text { RH }\end{array}$ & $\begin{array}{l}\text { Maximum wt\% } \\
\text { change at 93\% RH }\end{array}$ \\
\hline Raw tacrolimus & I.7I & 1.66 \\
DPPC & 11.40 & 13.19 \\
DPPG & 3.98 & 5.47 \\
Tacrolipo25 & 12.03 & $13.5 \mathrm{I}$ \\
Tacrolipo75 & $\mathrm{I} 1.66$ & 12.96 \\
\hline Abbreviations: & DPPC, dipalmitoylphosphatidylcholine; DPPG, sodium \\
dipalmitoylphosphatidylglycerol; RH, relative humidity.
\end{tabular}
dipalmitoylphosphatidylglycerol; $\mathrm{RH}$, relative humidity.

haps due to poor penetration into the lung in high enough therapeutic concentrations, as well as limitations of treatment by severe systemic toxicity. We have successfully demonstrated in our recent report the improved response in a lung transplant patient to inhaled nebulized tacrolimus for lung immunosuppression while significantly reducing systemic side effects, increasing local drug concentration in the smaller airways where BOS occurs, improving pulmonary function, and improving patient outcomes. ${ }^{25}$ The goal of this work was to rationally design dry powder inhalation delivery systems for localized tacrolimus therapy of the lung. We have also successfully developed a tacrolimus formulation with lung surfactant mimic phospholipids (DPPC and DPPG), which can offer lung surfactant replacement therapy, enhanced pulmonary immunity, and sustained release of drug. These formulations are biodegradable and biocompatible. However, rendering nanoparticles may potentially increase tacrolimus blood concentrations following aerosolization, due to possible translocation out of the lung to the blood.

Spray drying is the most commonly used method to prepare powders for inhalation. ${ }^{58,59}$ It was utilized for preparation and stabilization of particles with desirable properties for pulmonary administration to overcome constraints associated with the lyophilization technique, such as formation of hard cake, need of micronization, addition of coarse carriers for aerosolization, and heterogeneous size distribution pattern. Spray-drying parameters play an important role in DPI properties such as particle size, shape, topographical features, density, and moisture content.

DPIs also offer many important advantages in targeted pulmonary delivery, as described in depth by these authors. ${ }^{26,27,44,51,54,55}$ The deposition site in the respiratory tract and the performance of inhaled aerosols are influenced by the physicochemical properties of the inhaled particles, including particle size, size distribution, particle morphol- 
ogy, surface morphology, and residual water content. ${ }^{27,44,51,55}$ Inhaled particles with a particle size in the range of $1-5 \mu \mathrm{m}$ can efficiently target the deep lung region. ${ }^{39,60,61}$ To optimize or tailor the particle characteristics in the solid state, the operating parameters of the spray-drying process, such as solvent type (organic or aqueous), solute concentration, atomization pressure, feed properties, pump rate, gas type, gas flow rate, and drying temperature (inlet or outlet), can be modified. ${ }^{39,62}$ In this study, it is noticed that altering the pump rate resulted in a difference in the particle size (all respirable) and particle surface morphology.

Novel organic solution advanced spray-dried particles and co-spray-dried lung surfactant mimic liposphere particles all were successfully designed under our rationally chosen advanced spray-drying closed-mode conditions with particle size far below $5.0 \mu \mathrm{m}$, and all were unimodal with a narrow size distribution. This is the first report of such novel respirable particles for dry powder inhalation for lung immunosuppression. The morphology of the raw materials and the spray-dried particles was investigated, and the SEM micrographs illustrate that processing the solutions of tacrolimus by spray drying yielded spherical particles with the essential properties for inhalation delivery as DPIs. In our novel advanced organic solution spray-drying method, methanol was used to solubilize the drug as a dilute solution, which lowers the final particle size and also lowers the residual water content in the final respirable powders, which, in turn, enhances aerosol performance. Interestingly, all organic solution advanced spray-dried tacrolimus respirable particles were close to a spherical shape (ie, equivalent sphere particle morphology), but their surface morphology could be tailored based on the pump rate chosen.

Raw tacrolimus exhibited distinct characteristic peaks in XRPD diffractograms and melting peak in DSC thermograms, suggesting the crystal nature of the drug. After spray drying, the above peaks were not present in their corresponding graphs, indicating a change from the crystalline state to the amorphous state. These phase transitions were also observed by crosspolarizing light HSM. The loss of crystallinity in spray-dried tacrolimus is expected to enhance its bioavailability, as it has been reported that the pharmaceuticals that have lower crystallinity often resulted in higher solubility and bioavailability. ${ }^{51,63}$

Novel respirable tacrolimus lung surfactant mimic particles as DPIs of acceptable size and aerosol characteristics were successfully prepared by organic solution advanced co-spray drying a solution of tacrolimus, DPPC, and DPPG. To modify or optimize the particulate product characteristics, advantage can be taken of the operating parameters of the spray-drying process, such as atomization pressure, feed properties, feed rate, gas flow rate, and drying temperature (inlet or outlet). ${ }^{62}$ Low pump rates (eg, $10 \%, 25 \%$, and $50 \%$ ) generated respirable tacrolimus particles with a corrugated surface, whereas a high pump rate (eg, 75\%) yielded respirable particles with a relatively smooth surface. Theoretically, particles with a slightly rough surface can improve particle aerodynamic features by increasing air drag force and reducing particle interactions. ${ }^{64-66}$ Therefore, a pump rate at $50 \%$ was used to successfully design and produce respirable tacrolimus lung surfactant mimic particles with corrugated surface for targeted deep lung delivery as DPIs.

In addition to the surface modification of particles, the residual water content of the powders is influenced by the spray-drying conditions. This is another advantage in our rationale in selecting organic solution (alcohol) spray drying in closed mode using UHP nitrogen gas. The residual water content in tacrolimus and DPPC powders before spray drying was significantly higher than that in organic solution advanced co-spray-dried tacrolimus particles.

DSC thermal analysis was used to investigate the effect of preparation process on the thermotropic phase transitions of tacrolimus and lung surfactant phospholipids. It was found that raw materials exhibited apparent $T_{m}$ and other phase transition enthalpy, indicative of their crystalline nature. Interestingly, the thermogram for the developed formulations showed an absence of corresponding endotherm for tacrolimus, and is suggestive of the amorphous nature of tacrolimus in developed formulations. This was also reflected in their corresponding XRPD diffractograms. The phospholipid bilayer structure was preserved for all liposphere DPI formulations following organic solution co-spray drying, as confirmed by both DSC and XRPD.

\section{Conclusion}

In this study, we report for the first time that novel respirable tacrolimus particles as DPI formulations for pulmonary nanomedicine were rationally designed, successfully produced, and optimized by organic solution advanced spray drying and co-spray drying in closed mode from dilute alcohol solutions. The particle size, particle morphology, surface morphology, and residual water content of all of the spraydried and co-spray-dried particles were suitable for targeted respiratory drug delivery as DPIs. There were also changes of physical characteristic states after processing, according to the XRPD and DSC analysis. Spray drying of drug solution caused the loss of crystallinity in tacrolimus powders. It also resulted in a significant reduction of water content. Tacrolimus lung surfactant mimic particles consisting of synthetic lung surfactant phospholipids, DPPC and DPPG, 
were also rationally designed and optimized for pulmonary nanomedicine delivery as respirable dry powders by advanced organic solution co-spray drying in closed mode. Preservation of the phospholipid bilayer structure in the solid state in the inhalable powders was successfully achieved. The small particle size, unimodal narrow size distribution, particle morphology, surface morphology, and very low residual water content of co-spray-dried particles were all suitable for targeted deep lung respiratory drug delivery. These novel tacrolimus DPI formulations offer great potential in effectively improving the delivery of immunosuppressive drugs directly to the pulmonary tract of lung transplant patients while significantly reducing their systemic side effects.

\section{Acknowledgments}

Dr Dicky Yu (UK College of Agriculture) is thanked for SEM access. Dr Tonglei Li (UK College of Pharmacy) is thanked for XRPD and HSM access. Ms Linda Combs is thanked for assistance with proofing and editing.

\section{Disclosure}

The authors report no conflicts of interest in this work.

\section{References}

1. Trulock EP, Christie JD, Edwards LB, et al. Registry of the International Society for Heart and Lung Transplantation: twenty-fourth official adult lung and heart-lung transplantation report-2007. J Heart Lung Transplant. 2007;26(8):782-795.

2. Taylor DO, Edwards LB, Boucek MM, et al. Registry of the International Society for Heart and Lung Transplantation: twenty-fourth official adult heart transplant report-2007. J Heart Lung Transplant. 2007;26(8):769-781.

3. Boehler A, Estenne M. Post-transplant bronchiolitis obliterans. Eur Respir J. 2003;22(6):1007-1018.

4. Estenne M, Maurer JR, Boehler A, et al. Bronchiolitis obliterans syndrome 2001: an update of the diagnostic criteria. $J$ Heart Lung Transplant. 2002;21(3):297-310.

5. Hayes D Jr. A review of bronchiolitis obliterans syndrome and therapeutic strategies. J Cardiothorac Surg. 2011;6(92):1-9.

6. Hayes D Jr, Mansour HM, Kirkby S, Phillips AB. Rapid acute onset of bronchiolitis obliterans syndrome in a lung transplant recipient after respiratory syncytial virus infection. Transpl Infect Dis. 2012:1-3.

7. Yousem SA, Berry GJ, Cagle PT, et al. Revision of the 1990 working formulation for the classification of pulmonary allograft rejection: Lung Rejection Study Group. J Heart Lung Transplant. 1996;15(1 Pt 1):1-15.

8. Halloran PF, Homik J, Goes N, et al. The "injury response": a concept linking nonspecific injury, acute rejection, and long-term transplant outcomes. Transplant Proc. 1997;29(1-2):79-81.

9. Knoop C, Haverich A, Fischer S. Immunosuppressive therapy after human lung transplantation. Eur Respir J. 2004;23(1):159-171.

10. Kobashigawa JA, Patel J, Furukawa H, et al. Five-year results of a randomized, single-center study of tacrolimus vs microemulsion cyclosporine in heart transplant patients. J Heart Lung Transplant. Apr 2006;25(4):434-439.

11. Briffa N, Morris RE. New immunosuppressive regimens in lung transplantation. Eur Respir J. 1997;10(11):2630-2637.

12. van den Berg JW, Postma DS, Koeter GH, van der Bij W. New immunosuppressive drugs and lung transplantation: last or least? Thorax. 1999;54(6):550-553.
13. Wiederrecht G, Lam E, Hung S, Martin M, Sigal N. The mechanism of action of FK-506 and cyclosporin A. Ann N Y Acad Sci. 1993;696:9-19.

14. Siekierka JJ, Sigal NH. FK-506 and cyclosporin A: immunosuppressive mechanism of action and beyond. Curr Opin Immunol. 1992;4(5): $548-552$.

15. Rondeau E. Mechanism of action of the new immunosuppressants: cyclosporin A, FK 506 and rapamycin. Nephrologie. 1992; 13(3): 137 .

16. Kino T, Hatanaka H, Hashimoto M, et al. FK-506, a novel immunosuppressant isolated from a Streptomyces. I. Fermentation, isolation, and physico-chemical and biological characteristics. J Antibiot (Tokyo). 1987;40(9):1249-1255.

17. Keicho N, Sawada S, Kitamura K, Yotsumoto H, Takaku F. Effects of an immunosuppressant, FK506, on interleukin 1 alpha production by human macrophages and a macrophage-like cell line, U937. Cell Immunol. 1991;132(2):285-294.

18. Sakr MF, McClain CJ, Gavaler JS, Zetti GM, Starzl TE, Van Thiel DH. FK 506 pre-treatment is associated with reduced levels of tumor necrosis factor and interleukin 6 following hepatic ischemia/reperfusion. J Hepatol. 1993;17(3):301-307.

19. Clardy J. The chemistry of signal transduction. Proc Natl Acad Sci USA. 1995;92(1):56-61.

20. Almawi WY, Melemedjian OK. Clinical and mechanistic differences between FK506 (tacrolimus) and cyclosporin A. Nephrology, Dialysis, Transplantation. 2000;15(12):1916-1918.

21. Borro J, Bravo C, Solé A, et al. Conversion from cyclosporine to tacrolimus stabilizes the course of lung function in lung transplant recipients with bronchiolitis obliterans syndrome. Transplant Proc. 2007;39(7): 2416-2419.

22. Canadas O, Guerrero R, Garcia-Canero R, Orellana G, Menendez M, Casals C. Characterization of liposomal tacrolimus in lung surfactantlike phospholipids and evaluation of its immunosuppressive activity. Biochemistry. 2004;43(30):9926-9938.

23. Taketomo C, Hodding J, Kraus D. Pediatric Dosage Handbook, 16th ed. Hudson, OH: American Pharmacists Association; 2009:1173.

24. Kur F, Reichenspurner H, Meiser BM, et al. Tacrolimus (FK506) as primary immunosuppressant after lung transplantation. Thorac Cardiovasc Surg. 1999;47(3):174-178.

25. Hayes D Jr, Zwischenberger JB, Mansour HM. Aerosolized tacrolimus in a lung transplant recipient. Transplant Proc. 2010;42(9): 3876-3879.

26. Park CW, Hayes D Jr, Mansour HM. Pulmonary inhalation aerosols for targeted antibiotics drug delivery. invited paper. European Pharmaceutical Review. 2011;16(1):32-36.

27. Hickey AJ, Mansour HM. Chapter 5: delivery of drugs by the pulmonary route. In: Florence AT, Siepmann J, editors. Modern Pharmaceutics, 5th ed. New York: Taylor and Francis, Inc; 2009;2:191-219.

28. Patton JS, Byron PR. Inhaling medicines: delivering drugs to the body through the lungs. Nat Rev Drug Discov. 2007;6(1):67-74.

29. Iacono AT, Corcoran TE, Griffith BP, et al. Aerosol cyclosporin therapy in lung transplant recipients with bronchiolitis obliterans. Eur Respir J. 2004;23(3):384-390.

30. Niven R. Toward managing chronic rejection after lung transplant: the fate and effects of inhaled cyclosporine in a complex environment. $A d v$ Drug Deliv Rev. 2011;63(1-2):88-109.

31. Corcoran TE. Inhaled delivery of aerosolized cyclosporine. Adv Drug Deliv Rev. 2006;58(9-10):1119-1127.

32. Mansour H, Wang DS, Chen CS, Zografi G. Comparison of bilayer and monolayer properties of phospholipid systems containing dipalmitoylphosphatidylglycerol and dipalmitoylphosphatidylinositol. Langmuir. 2001;17(21):6622-6632.

33. Morrow MR, Temple S, Stewart J, Keough KM. Comparison of DPPC and DPPG environments in pulmonary surfactant models. Biophys $J$. 2007;93(1):164-175.

34. Mansour HM, Zografi G. Relationships between equilibrium spreading pressure and phase equilibria of phospholipid bilayers and monolayers at the air-water interface. Langmuir. 2007;23(7):3809-3819. 
35. Mansour HM, Damodaran S, Zografi G. Characterization of the in situ structural and interfacial properties of the cationic hydrophobic heteropolypeptide, $\mathrm{KL}_{4}$, in lung surfactant bilayer and monolayer models at the air-water interface: implications for pulmonary surfactant delivery. Mol Pharm. 2008;5(5):681-695.

36. Goerke J. Pulmonary surfactant: functions and molecular composition. Biochim Biophys Acta. 1998;1408(2-3):79-89.

37. Veldhuizen R, Nag K, Orgeig S, Possmayer F. The role of lipids in pulmonary surfactant. Biochim Biophys Acta. 1998;1408(2-3):90-108.

38. Postle AD, Heeley EL, Wilton DC. A comparison of the molecular species compositions of mammalian lung surfactant phospholipids. Comp Biochem Physiol A Mol Integr Physiol. 2001;129(1):65-73.

39. Mansour HM, Rhee YS, Wu X. Nanomedicine in pulmonary delivery. Int J Nanomedicine. 2009;4:299-319.

40. Mansour HM, Rhee YS, Park CW, DeLuca PP. Lipid nanoparticulate drug delivery and nanomedicine. In: Moghis A, editor. Lipids in Nanotechnology, 1st ed. Urbana, IL: American Oil Chemists Society (AOCS) Press; 2011:221-268.

41. Mansour HM, Park CW, Hayes D Jr. Nanoparticle lung delivery and inhalation aerosols for targeted pulmonary nanomedicine. In: Kumar A, Mansour HM, Friedman A, Blough E, editors. Nanomedicine in Drug Delivery. London, UK: CRC Press/Taylor Francis, Inc; 2013. In press.

42. Rhee YS, Mansour HM. Nanopharmaceuticals I: nanocarrier systems in drug delivery. Invited paper. Int J Nanotechnol. 2011;8(1-2):84-114.

43. Wu X, Mansour HM. Nanopharmaceuticals II: application of nanoparticles and nanocarrier systems in pharmaceutics and nanomedicine. Invited paper. Int J Nanotechnol. 2011;8(1-2):115-145.

44. Hickey AJ, Mansour HM. Formulation challenges of powders for the delivery of small molecular weight molecules as aerosols. In: Rathbone MJ, Hadgraft J, Roberts MS, Lane ME, editors. ModifiedRelease Drug Delivery Technology, 2nd ed. New York: Informa Healthcare; 2008;2:573-602.

45. Li X, Mansour HM. Physicochemical characterization and water vapor sorption of organic solution advanced spray-dried inhalable trehalose microparticles and nanoparticles for targeted dry powder pulmonary inhalation delivery. AAPS PharmSciTech. 2011;12(4):1420-1430.

46. Meenach SA, Vogt FG, Anderson KW, Hilt JZ, McGarry RC, Mansour HM. Design, physicochemical characterization, and optimization of organic solution advanced spray-dried inhalable dipalmitoylphosphatidylcholine (DPPC) and dipalmitoylphosphatidylethanolamine poly(ethylene glycol) (DPPE-PEG) microparticles and nanoparticles for targeted respiratory nanomedicine delivery as dry powder inhalation aerosols. Int J Nanomedicine. 2013;8:275-293.

47. Canadas O, Guerrero R, Garcia-Canero R, Orellana G, Menendez M, Casals C. Characterization of liposomal tacrolimus in lung surfactantlike phospholipids and evaluation of its immunosuppressive activity. Biochemistry. 2004;43(30):9926-9938.

48. Xu Z, Mansour HM, Mulder T, McLean R, Langridge J, Hickey AJ. Dry powder aerosols generated by standardized entrainment tubes from drug blends with lactose monohydrate: 2 . Ipratropium bromide monohydrate and fluticasone propionate. J Pharm Sci. 2010;99(8): 3415-3429.

49. Mansour HM, Xu Z, Hickey AJ. Dry powder aerosols generated by standardized entrainment tubes from alternative sugar blends: 3 . Trehalose dihydrate and D-mannitol carriers. J Pharm Sci. 2010;99(8): $3430-3441$
50. Park CW, Rhee YS, Vogt F, et al. Advances in microscopy and complementary imaging techniques to assess the fate of drugs ex-vivo in respiratory drug delivery. Invited Paper. Adv Drug Deliv Rev. 2012;64(4):344-356.

51. Hickey AJ, Mansour HM, Telko MJ, et al. Physical characterization of component particles included in dry powder inhalers. I. Strategy review and static characteristics. J Pharm Sci. 2007;96(5):1282-1301.

52. Mansour HM, Zografi G. The relationship between water vapor absorption and desorption by phospholipids and bilayer phase transitions. J Pharm Sci. 2007;96(2):377-396.

53. Xu Z, Mansour HM, Mulder T, McLean R, Langridge J, Hickey AJ. Dry powder aerosols generated by standardized entrainment tubes from drug blends with lactose monohydrate: 1. Albuterol sulfate and disodium cromoglycate. J Pharm Sci. 2010;99(8):3398-3414.

54. Willis L, Hayes D Jr, Mansour HM. Therapeutic liposomal dry powder inhalation aerosols for targeted lung delivery. Lung. 2012;190(3):251-262.

55. Wu X, Li X, Mansour HM. Surface analytical techniques in solid-state particle characterization: implications for predicting performance in dry powder inhalers. Invited paper. KONA Powder and Particle Journal. 2010;28:3-19.

56. Xu Z, Mansour HM, Hickey AJ. Particle interactions in dry powder inhaler unit processes. $J$ Adhes Sci Technol. 2011;25(4-5):451-482.

57. Alves GP, Santana MHA. Phospholipid dry powders produced by spray drying processing: structural, thermodynamic and physical properties. Powder Technol. 2004;145:139-148.

58. Andya JD, Maa YF, Costantino HR, et al. The effect of formulation excipients on protein stability and aerosol performance of spray-dried powders of a recombinant humanized anti-IgE monoclonal antibody. Pharm Res. 1999;16(3):350-358.

59. Sollohub K, Cal K. Spray drying technique: II. Current applications in pharmaceutical technology. J Pharm Sci. 2010;99(2):587-597.

60. Yu J, Chien YW. Pulmonary drug delivery: physiologic and mechanistic aspects. Crit Rev Ther Drug Carrier Syst. 1997;14(4):395-453.

61. Schulz H. Mechanisms and factors affecting intrapulmonary particle deposition: implications for efficient inhalation therapies Holger Schulz. Pharm Sci Technol Today. 1998;1(8):326-344.

62. Master L. Spray Drying Handbook, 5th ed. New York: Longman; 1991.

63. Li DX, Oh YK, Lim SJ, et al. Novel gelatin microcapsule with bioavailability enhancement of ibuprofen using spray-drying technique. Int $J$ Pharm. 2008;355(1-2):277-284.

64. Chew NY, Chan HK. Use of solid corrugated particles to enhance powder aerosol performance. Pharm Res. 2001;18(11):1570-1577.

65. Chew NY, Tang P, Chan HK, Raper JA. How much particle surface corrugation is sufficient to improve aerosol performance of powders? Pharm Res. 2005;22(1):148-152.

66. Maa YF, Costantino HR, Nguyen PA, Hsu CC. The effect of operating and formulation variables on the morphology of spray-dried protein particles. Pharm Dev Technol. 1997;2(3):213-223.
Drug Design, Development and Therapy

\section{Publish your work in this journal}

Drug Design, Development and Therapy is an international, peerreviewed open-access journal that spans the spectrum of drug design and development through to clinical applications. Clinical outcomes, patient safety, and programs for the development and effective, safe, and sustained use of medicines are a feature of the journal, which

\section{Dovepress}

has also been accepted for indexing on PubMed Central. The manuscript management system is completely online and includes a very quick and fair peer-review system, which is all easy to use. Visit $\mathrm{http}: / /$ www.dovepress.com/testimonials.php to read real quotes from published authors.

Submit your manuscript here: http://www.dovepress.com/drug-design-development-and-therapy-journal 